\title{
MEGALOMICIN, A NEW MACROLIDE ANTIBIOTIC COMPLEX PRODUCED BY MICROMONOSPORA
}

\author{
Marvin J. Weinstein, Gerald H. Wagman, \\ Joseph A. Marquez, Raymond T. Testa, \\ Edwin Oden and J. Allan Waitz \\ Department of Microbiology, Schering Corporation \\ Bloomfield, New Jersey, U.S.A.
}

(Received for publication March 25, 1969)

\begin{abstract}
A new macrolide antibiotic complex has been isolated from fermentation broths of two strains of a new species of Micromonospora, M. megalomicea sp. n. The antibiotic complex has been differentiated from other known macrolides and methods for its production, isolation and separation of components have been devised. Like other macrolides, it is primarily active against gram-positive bacteria and is more active at an alkaline $\mathrm{pH}$. Of the four known components, megalomicin $\mathrm{A}$ has been studied most extensively. It has activity equal to or slightly less than that of erythromycin both in vitro and in vivo. In dogs dosed orally, it is better tolerated and gives higher peak serum levels with a much greater duration than erythromycin.
\end{abstract}

In a continuing search to examine the micromonospora as producers of antimicrobial substances, a new member of the genus was found which produces a novel macrolide antibiotic complex ${ }^{1)}$. This new antibiotic complex has been named megalomicin and was isolated from fermentation broths of two strains of a new species of Micromonospora. This report presents initial data concerning the chemical and biological characteristics of the novel complex produced. Earlier studies have revealed the micromonospora to produce a variety of antibiotics. ${ }^{2,3,4)}$

\section{Materials and Methods}

The organism producing the megalomicin complex has been named Micromonospora megalomicea sp. n.; taxonomic studies establishing the validity of this novel species on the basis of biochemical and morphological characteristics are in preparation. Two. strains have been found which are natural color variants and are distinguished microscopically by the degree to which sporulation occurs. Cultures of the organisms have been deposited in the stock culture collection of the U.S. Department of Agriculture, Northern Utilization Research and Development Division, Peoria, Illinois, where they have been designated as NRRL 3274 and NRRL 3275.

For laboratory production of megalomicin, the growth from an agar slant is inoculated into flasks containing a germination medium with the composition as shown in Table 1 . This is incubated at $35^{\circ} \mathrm{C}$ for 72 hours on a rotary shaker. A $5 \%$ inoculum is transferred to a fermentation medium (Table 1) and incubated for $60 \sim 70$ hours at $31^{\circ} \mathrm{C}$ in shake flasks or in fermentors.

Antibiotic potencies were determined by means of a cylinder cup agar diffusion assay similar to that described for erythromycin ${ }^{5)}$ for which Sarcina lutea ATCC 9341 was the 
Table 1. Media for production of megalomicins

\begin{tabular}{ll|lr}
\hline \multicolumn{2}{c|}{ Germination medium } & \multicolumn{2}{c}{ Fermentation medium } \\
\hline Bacto beef extract (Difco) & $3.0 \mathrm{~g} /$ liter & Bacto yeast extract (Difco) & $5.0 \mathrm{~g} / \mathrm{liter}$ \\
Bacto tryptone (Difco) & 5.0 & Dextrose & 10.0 \\
Dextrose & 1.0 & Starch & 20.0 \\
Potato starch & 24.0 & Casein hydrolysate & 5.0 \\
Bacto yeast extract (Difco) & 5.0 & CaCO & 4.0 \\
$\mathrm{CaCO}_{3}$ & 2.0 & Tap water & Q.S. \\
Tap water & Q.S. & & \\
\hline
\end{tabular}

test organism. A unit of activity of the megalomicin complex is the amount of material which produces a zonal response of $17.8 \pm 0.5 \mathrm{~mm}$ under the conditions of this assay, and has been defined as one microgram.

For determinations of in vitro sensitivity, all test organisms were incubated in yeastbeef broth at $37^{\circ} \mathrm{C}$ for $18 \sim 20$ hours, except where indicated.

Animal studies were carried out in CF-1 male albino mice weighing $18 \sim 20 \mathrm{~g}$ each and beagle type dogs of both sexes weighing approximately $10 \mathrm{~kg}$ each. Drug suspensions were prepared in $0.5 \%$ aqueous carboxymethyl cellulose and ultrasonicated to reduce particle size. In therapeutic tests, animals were treated twice, shortly before and 4 hours after intraperitoneal challenge with approximately $10^{7}$ organisms/mouse. Control infected mice died in 18 24 hours. Survivors in treated groups were determined 48 hours after infection. $\mathrm{PD}_{50}$ and $\mathrm{LD}_{50}$ values were determined by probit procedures.

\section{Results and Discussion}

\section{Isolation and Characterization}

The megalomicin complex can be isolated by adjusting the fermentation broth to $\mathrm{pH}$ 9.5, extracting with ethyl acetate, and concentrating to a small volume. Partial purification is achieved by chromatography on a column of LH 20 Sephadex using aqueous ethanol as the eluent. Active fractions are combined, concentrated and additional impurities removed by precipitation with petroleum ether (b. p. $30 \sim 60^{\circ} \mathrm{C}$ ).

Megalomicin has been shown to be different from other antibiotics except the macrolide group by paper and thin-layer chromatography. Studies to be reported in this paper and additional chemical data ${ }^{6)}$ clearly indicated the antibiotic to be a novel desosamine-containing macrolide. By thin-layer chromatography on silica gel G plates, megalomicin can be readily differentiated from other macrolide antibiotics as seen in Table 2 . Although the Rf's of the

Table 2. Comparative thin-layer chromatography of megalomicin and other macrolides

\begin{tabular}{|c|c|c|c|c|c|}
\hline System & Antibiotic & \multicolumn{3}{|c|}{ Rf-Spot color* } & $\begin{array}{c}\mathrm{Kt} \\
\text { Inhibition } \\
\text { zone }\end{array}$ \\
\hline \multirow{4}{*}{ I } & Megalomicin & & 0.98 & blue-black & 0.98 \\
\hline & Oleandomycin & & 0.98 & green & 0.98 \\
\hline & Erythromycin & & 0.98 & yellow-tan & 0.98 \\
\hline & Magnamycin & & 0.98 & blue-purple & 0.98 \\
\hline \multirow{5}{*}{ II } & Megalomicin & & 0.13 & red-purple & 0.13 \\
\hline & Erythromycin & & 0.26 & green-brown & 0.26 \\
\hline & Spiramycin & 0.06 & 0.30 & purple, green & 0.06 \\
\hline & Oleandomycin & & 0.19 & green & 0.19 \\
\hline & Magnamycin & 0.40 & 0.47 & purple, red-purple & 0.40 \\
\hline
\end{tabular}

$* \mathrm{H}_{2} \mathrm{SO}_{4}$ spray, heat at $100^{\circ} \mathrm{C}$ for $3 \sim 5$ minutes.

Plated against $S$. aureus ATCC $6538 \mathrm{P}$

Solvent system: I; $\mathrm{CHCl}_{3}$ - methanol $-17 \% \mathrm{NH}_{4} \mathrm{OH}(2: 1: 1)$. II; Butanol - acetic acid - water $(3: 1: 1)$. 
macrolides in the chlorof orm-methanol-ammonia system are identical, distinct differences in the colors of the spots are produced by use of a sulfuric acid spray and subsequent heating. In the butanol-acetic acid-water system, differences in $\mathrm{Rf}$ values and colors are seen. Thin-layer chromatography in a solvent system consisting of 60 parts chloroform to 40 parts methanol, indicates that megalomicin is composed of four major active components (Fig. 1). These are identified as A, $\mathrm{B}, \mathrm{C}_{1}$, and $\mathrm{C}_{2}$ respectively. The complex was assigned a potency of 1,000 units/mg by the previously described assay. Separation of these four megalomicin components has been presented.6,7) In the assay described, the components exhibit the following potencies: $A=625$ units/mg; $B=305$ units/mg; $\mathrm{C}_{1}=3,800$ units/mg; $\mathrm{C}_{2}=$ 4,800 units/mg. Each pure component base has been assigned a potency of $1,000 \mathrm{mcg} / \mathrm{mg}$ and all subsequent assays are based on their respective base component standards.

The megalomicin components are generally soluble in polar organic solvents such as ethanol, acetone and methanol with only slight water solubility.

Megalomicins $\mathrm{A}$ and $\mathrm{B}$ are stable from $\mathrm{pH} 6$ to 10

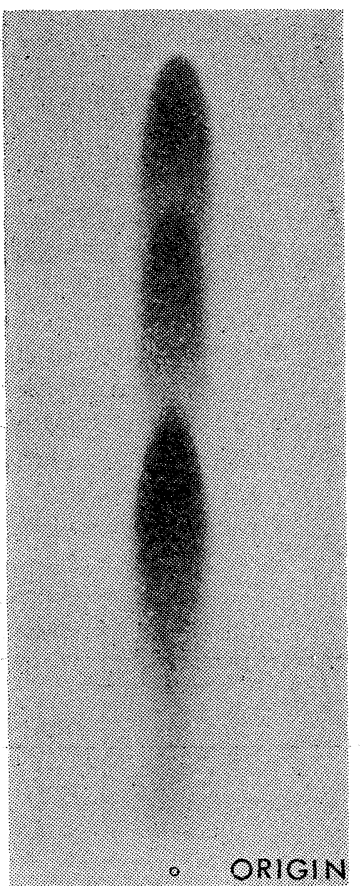

Fig. 1. Thin-layer chromatogram of megalomicin complex, silica gel G, chloroform - methanol (3:2) solvent system. Visualized by sulfuric acid spray. Components are, from origin, $\mathrm{A}, \mathrm{B}, \mathrm{C}_{1}$ and $\mathrm{C}_{2}$ respectively. and the $\mathrm{C}_{1}$ and $\mathrm{C}_{2}$ components are stable from $\mathrm{pH} 4$ to 10 at temperatures up to $100^{\circ} \mathrm{C}$ for 30 minutes when tested against $B$. subtilis.

Due to the development of a simple method of conversion, as described elsewhere ${ }^{7)}$, megalomicin A has been studied most extensively. Much of the remainder of this paper will deal primarily with megalomicin A as the base.

\section{In Vitro Activity}

The megalomicin complex has in vitro activity against a variety of gram-positive bacteria with minimal activity against gram-negative bacteria (Table 3 ). The megalomicin complex has activity approximately equal to or $1 / 2$ that of erythromycin depending upon the organism.

As shown in Table 4, the 4 megalomicin components have a similar spectrum of activity. The $\mathrm{C}_{2}$ component is most active and the $\mathrm{B}$ component is least active. The A component has the highest activity against gram-negative bacteria.

Clinical isolates of Staphylococcus and Streptococcus strains which are resistant to erythromycin were, with only one exception (strain 386), cross-resistant to megalomicin (Table 5).

As with other macrolides, megalomicin had greatly enhanced activity at higher $\mathrm{pH}$ levels.

Serum has a variable effect on the in vitro activity of megalomicin; occasionally minimum inhibitory concentration (MIC) values are increased in the presence of 
Table 3, In vitro activity of megalomicin complex and erythromycin base*

\begin{tabular}{l|c|c|c}
\hline \multirow{2}{*}{ Organism } & \multicolumn{2}{|c}{ MIC (mcg/ml) } \\
\cline { 2 - 4 } & $\begin{array}{c}\text { No. } \\
\text { Strains }\end{array}$ & Megalomicin complex & Erythromycin base \\
\hline Bacillus subtilis & 1 & 0.03 & 0.03 \\
Bacillus megaterium & 1 & 0.3 & 0.08 \\
Diplococcus pneumoniae & 2 & $0.05 \sim 0.5$ & $0.05 \sim 0.2$ \\
Enterococcus sp. & 3 & 0.3 & 0.006 \\
Sarcina lutea & 1 & 0.008 & 0.75 \\
Staphylococcus aureus & 10 & $0.03 \sim 0.3$ & 0.005 \\
Streptococcus faecalis & 1 & 0.3 & 0.3 \\
Streptococcus pyogenes & 3 & $0.3 \sim 0.75$ & 7.0 \\
Mycobacterium smegmatis & 1 & 0.7 & 7.5 \\
Escherichia coli & 1 & 6.0 & 17.5 \\
Klebsiella pneumoniae & 1 & 12.0 & 12.5 \\
Proteus vulgaris & 1 & 6.0 & 7.5 \\
Pseudomonas aeruginosa & 1 & 6.0 & 0.3 \\
Salmonella schottmuelleri & 6.0 & 0.0 \\
\hline
\end{tabular}

* Medium: Yeast-beef broth, pH 7.8.

Table 4. In vitro activity of megalomicin components*

\begin{tabular}{|c|c|c|c|c|c|}
\hline \multirow{2}{*}{ Organism } & \multirow{2}{*}{$\begin{array}{c}\text { No. } \\
\text { Strains }\end{array}$} & \multicolumn{4}{|c|}{ MIC $\quad(\mathrm{mcg} / \mathrm{ml})$} \\
\hline & & A & B & $\mathrm{C}_{1}$ & $\mathrm{C}_{2}$ \\
\hline Bacillus subtilis & 1 & 0.3 & 0.05 & 0.3 & 0.005 \\
\hline Bacillus megaterium & 1 & 0.75 & 1.2 & 0.75 & 0.6 \\
\hline Diplococcus pneumoniae & 2 & $\sim 1.2$ & $0.5 \sim 1.2$ & $0.5 \sim 1.2$ & $0.05 \sim 0.6$ \\
\hline Enterococcus sp. & 3 & 0.3 & $0.2 \sim 0.6$ & 0.3 & $0.03 \sim 0.6$ \\
\hline Sarcina lutea & 1 & 0.02 & 0.005 & 0.003 & 0.0005 \\
\hline Staphylococcus aureus & 10 & $0.075 \sim 0.75$ & $0.2 \sim 0.6$ & $0.01 \sim 0.75$ & $0.03 \sim 0.6$ \\
\hline Streptococcus faecalis & 1 & 0.075 & 0.1 & 0.075 & 0.005 \\
\hline Streptococcus pyogenes & 3 & 0.75 & $0.2 \sim 5.0$ & $0.3 \sim 0.75$ & $0.03 \sim 0.6$ \\
\hline Mycobacterium smegmatis & 1 & 0.3 & 5.0 & 0.3 & 0.05 \\
\hline Escherichia coli & 1 & 3.0 & 12.0 & 7.5 & 12.0 \\
\hline Klebsiella pneumoniae & 1 & 6.0 & 24.0 & 12.5 & 24.0 \\
\hline Proteus vulgaris & 1 & 6.0 & 24.0 & 12.5 & 24.0 \\
\hline Pseudomonas aeruginosa & 1 & 3.0 & 12.0 & 7.5 & 6.0 \\
\hline Salmonella schottmuelleri & 1 & 3.0 & 12.0 & 7.5 & 12.0 \\
\hline
\end{tabular}

* Medium: Yeast beef broth, pH 7.8.

Table 5. In vitro activity of megalomicin against erythromycin resistant clinical isolates*

\begin{tabular}{c|c|c|c}
\hline \multirow{2}{*}{ Organism } & \multicolumn{3}{|c}{ MIC (mcg/ml) } \\
\cline { 2 - 4 } & Megalomicin A & Megalomicin $C_{1}$ & Erythromycin base \\
\hline Staphylococcus aureus DA 2033 & $>32.0$ & $>32.0$ & $>32.0$ \\
Staphylococcus aureus DA 303 & 18.0 & 38.0 & 38.0 \\
Staphylococcus aureus DA 309 & 38.0 & 38.0 & 38.0 \\
Staphylococcus aureus DA 383 & $>75.0$ & 18.0 & 75.0 \\
Staphylococcus aureus DA 386 & $>75.0$ & 3.0 & 63.0 \\
Staphylococcus aureus DA 388 & $>75.0$ & 63.0 & 63.0 \\
Staphylococcus aureus DA 426 & $>75.0$ & 75.0 & 7.5 \\
Streptococcus pyogenes DC 9 & $>75.0$ & 75.0 & 75.0 \\
Streptococcus pyogenes DC 31 & $>75.0$ & 63.0 & 75.0 \\
Streptococcus pyogenes DC 33 & $>75.0$ & 18.0 & 75.0 \\
Streptococcus pyogenes DC 76 & 18.0 & 38.0 & 8.0 \\
Streptococcus pyogenes DC 77 & 18.0 & 18.0 & 18.0 \\
Streptococcus pyogenes DC 80 & 18.0 & 8.0 \\
\hline
\end{tabular}

* Medium: Yeast beef broth, $\mathrm{pH} 7.8$. 
serum. Serum binding is of the same order as erythromycin and when determined by dialysis ranged from 20 to $30 \%$ for the megalomicin components. As with erythromycin, megalomicin is bactericidal against some organims and only bacteristatic against others.

\section{In Vivo Activity}

The acute toxicity of megalomicin A base in male Carworth CF-1 mice is shown in Table 6 in comparison with erythromycin base. Both antibiotics were found to have similar toxicities. Mice tolerated daily subcutaneous doses of $500 \mathrm{mg} / \mathrm{kg} /$ day for 21 days with only slight initial weight loss.

As shown in Table 7, megalomicin A base was tested for protective activity against a variety of acute lethal infections in mice. As with erythromycin, megalomicin A was more active parenterally than orally. Megalomicin has the same or $1 / 2$ the activity of erythromycin against gram-positive infections, depending on the organism, and is slightly more active than erythromycin against gram-negative infections.

The absorption of megalomicin A base was compared with erythromycin base in dogs after a single oral dose of $500 \mathrm{mg} / \mathrm{dog}$ which approximated $50 \mathrm{mg} / \mathrm{kg}$ (Table 8).

Megalomicin A base was well tolerated while erythromycin base was emetic in approximately $1 / 2$ of the dogs studied. The data in Table 8 are averages from 9 dogs dosed with megalomicin A base and 7 dogs dosed with erythromycin base. Only dogs in which emesis did not occur are included for erythromycin.

Table 6. Acute toxicity of megalomicin A and erythromycin base in mice

\begin{tabular}{c|c|c|c}
\hline & Route & Megalomicin A base & Erythromycin base \\
\hline \multirow{2}{*}{ Acute $\mathrm{LD}_{50}(\mathrm{mg} / \mathrm{kg})$} & Oral & 7,500 & 7,500 \\
& S. C. & 7,000 & 8,000 \\
& I. P. & 350 & 500 \\
\hline Subacute $\mathrm{LD}_{50}(\mathrm{mg} / \mathrm{kg} / \mathrm{day})$ & S. C. 21 days & $>500$ & $>500$ \\
\hline
\end{tabular}

Table 7. Protective activity of megalomicin A and erythromycin in mice*

\begin{tabular}{l|c|c|r|r}
\hline \multirow{2}{*}{\multicolumn{1}{c}{ Infecting organism }} & \multicolumn{3}{|c}{$\mathrm{PD}_{50}(\mathrm{mg} / \mathrm{kg})$} \\
\cline { 2 - 5 } & \multicolumn{2}{|c|}{ Megalomicin A } & \multicolumn{2}{|c}{ Erythromycin } \\
\cline { 2 - 5 } & Oral & S. C. & Oral & S. C. \\
\hline Streptococcus pyogenes No. 22 & 180 & 180 & 100 & 50 \\
Streptococcus pyogenes No. 9 & 250 & 167 & 53 & 140 \\
Staphylococcus aureus W & 117 & 20 & 75 & 20 \\
Staphylococcus aureus No. 41 & 150 & 20 & 134 & 75 \\
Diplococcus pneumoniae No. 2 & 250 & 70 & $>250$ & 160 \\
Escherichia coli ATCC 10536 & 200 & 100 & $>250$ & $>250$ \\
Klebsiella pneumoniae DA 20 & 250 & 150 & $>250$ & 130 \\
Pseudomonas aeruginosa ATCC 8689 & $>250$ & 161 & & 75 \\
\hline
\end{tabular}

* Each preparation was tested as a suspension in $0.5 \%$ carboxymethyl cellulose. Treatment was divided into two doses and given 30 minutes before and 4 hours after intraperitoneal infection. Survivors were determined 48 hours after infection. 
Table 8. Oral absorption in dogs after a single dose $(50 \mathrm{mg} / \mathrm{kg}) *$

\begin{tabular}{|c|c|c|c|c|c|c|c|c|c|c|c|}
\hline & \multirow{2}{*}{$\begin{array}{c}\text { No. } \\
\text { Dogs }\end{array}$} & \multicolumn{10}{|c|}{ Serum levels $(\mathrm{mcg} / \mathrm{ml})$ at time (hrs.) } \\
\hline & & 0 & 1 & 2 & 4 & & & 24 & 48 & 72 & 96 \\
\hline Megalomicin A base & 9 & 0 & 9.3 & 7.8 & 3.5 & & & 0.8 & 0.3 & 0.3 & 0 \\
\hline \multirow[t]{3}{*}{ Erythromycin base } & 7 & 0 & 4.9 & 3.6 & 1.9 & & & 0 & 0 & 0 & - \\
\hline & No. & \multicolumn{5}{|c|}{ Urine levels total $\mathrm{mg}$ excreted } & & \multicolumn{4}{|c|}{ Percent of dose excreted } \\
\hline & Dogs & \multicolumn{2}{|c|}{$0 \sim 24 \mathrm{hrs}}$. & \multicolumn{3}{|c|}{$25 \sim 48 \mathrm{hrs}}$. & & \multicolumn{2}{|c|}{$0 \sim 24 \mathrm{hrs}}$. & \multicolumn{2}{|c|}{$48 \mathrm{hrs}}$. \\
\hline Megalomicin A base & 9 & \multicolumn{2}{|c|}{65.2} & \multicolumn{3}{|c|}{15.4} & & \multicolumn{2}{|l|}{13.0} & \multicolumn{2}{|c|}{3.0} \\
\hline Erythromycin base & 7 & \multicolumn{2}{|r|}{59.7} & \multicolumn{3}{|c|}{0.5} & & \multicolumn{2}{|l|}{11.9} & \multicolumn{2}{|c|}{0.1} \\
\hline
\end{tabular}

* Drug was administered in gelatin capsules.

Megalomicin A base was absorbed considerably better than erythromycin in dogs, resulting in higher peak levels and serum levels of greater duration. The prolonged blood levels are also reflected by urine levels, in particular the considerable amount excreted in the 25 48 hour period in dogs given megalomicin $\mathrm{A}$ base.

\section{Literature Cited}

1) Weinstein, M. J.; G. H. Wagman, J. Marquez, G. Luedemann, E. Oden \& J. A. Waitz: Megalomicin. I. New Micromonospora-produced macrolide antibiotic complex. Abstracts of Papers, Eighth Interscience Conference on Antimicrobial Agents and Chemotherapy p. 4, 1968 (Oct. 21 23, 1968, New York)

2) Weinstein, M. J.; G. M. Luedemann, E. M. Oden \& G. H. Wagman: Gentamicin, a new broadspectrum antibiotic complex. Antimicr. Agents \& Chemoth. -1963:1 7, 1964.

3) Weinstein, M. J.; G. M. Luedemann, E. M. Oden \& G. H. Wagman: Everninomicin, a new antibiotic complex from Micromonospora carbonacea. Antimicr. Agents \& Chemoth. -1964:24 32, 1965.

4) Weinstein, M. J.; G. M. Luedemann, E. M. Oden \& G. H. Wagman: Halomicin, a new Micromonospora-produced antibiotic. Antimicr. Agents \& Chemoth. -1967: 435 441, 1968.

5) Grove, D. C. \& W. A. Randall: Assay methods of antibiotics, a laboratory manual. Medical Encyclopedia Inc., New York, 1955.

6) Marquez, J.; G. H. Wagman, R. T. Testa \& M. J. Weinstein: Megalomicin. II. Fermentation and isolation of the antibiotic. Abstracts of Papers, Eighth Interscience Conference on Antimicrobial Agents and Chemotherapy p. 4, 1968 (Oct. 21 23, 1968, New York)

7) Reimann, H.; R. S. Jaret \& A. K. Mallams: Megalomicin. III. Purification and chemical studies. Abstracts of Papers, Eighth Interscience Conference on Antimicrobial Agents and Chemotherapy p. 4, 1968 (Oct. 21 23, 1968, New York) 